Leveraging comprehensive baseline datasets to quantify property variability in nucleargrade graphites

Mark C. Carroll ${ }^{\mathrm{a}}$, William E. Windes ${ }^{\mathrm{a}}$, David T. Rohrbaugh ${ }^{\mathrm{a}}$, Joseph P. Strizak ${ }^{\mathrm{b}}$, and Timothy D. Burchell $^{\mathrm{b}}$ 


\title{
Leveraging comprehensive baseline datasets to quantify property variability in nuclear- grade graphites
}

\author{
Mark C. Carroll ${ }^{\mathrm{a}}$, William E. Windes ${ }^{\mathrm{a}}$, David T. Rohrbaugh ${ }^{\mathrm{a}}$, Joseph P. Strizak ${ }^{\mathrm{b}}$, and Timothy D. \\ Burchell $^{\mathrm{b}}$
}

\begin{abstract}
The full characterization of the physical and mechanical properties of candidate nuclear-grade graphites is highly dependent upon an understanding of the distribution of values that are inherent to graphite. Not only do the material properties of graphites vary considerably between grades owing to the raw materials sources, filler particle type and size, methods of compaction, and production process parameters, but variability is observed between billets of the same grade from a single batch and even across spatial positions within a single billet. Properly enveloping the expected properties of interest requires both a substantial amount of data to statistically capture this variability and a representative distribution capable of accurately describing the range of values. A two-parameter Weibull distribution is confirmed to be representative of the distribution of physical (density, modulus) and mechanical (compressive, flexure, and tensile strength) values in five different nuclear-grades of graphite. The fine-grained isomolded grades tend toward higher Weibull modulus and characteristic strength values, while the extruded grade being examined exhibits relatively large distributions in property values. With the number of candidate graphite specimens that can undergo full irradiation exposure and subsequent testing having limited feasibility with regard to economics and timely evaluations, a proper capture of the raw material variability in an unirradiated state can provide crucial supplementary resolution to the limited amount of available data on irradiated candidate grades.
\end{abstract}

\section{Key Words}

Graphite, mechanical properties, physical properties, variability, Weibull distribution 


\section{Introduction}

High-purity graphite is the core structural material of choice in the conceptual design for the Very High Temperature Reactor (VHTR), a graphite-moderated, helium-cooled configuration with outlet temperature capabilities that are anticipated to approach or exceed $950{ }^{\circ} \mathrm{C}$. The extensive production of thermal energy at these elevated temperatures enables not only more efficient electric power generation, but can also supply process heat for industrial applications that otherwise require large amounts of fossil fuel (Allen, 2008, U.S. DOE and GIF, 2002). While nuclear-grade graphite is an ideal core material for this design, based upon an extremely high-temperature capability coupled with an optimum combination of thermal stability, machinability, and low cost, the quasi-brittle mechanical properties of graphite have been shown to exhibit a relatively large amount of scatter in measured strength levels (Hindley, 2013, Nemeth, 2010). The mechanical response of nuclear graphites is highly dependent upon the inherent defect structure, composed of boundaries between filler particles, pores, voids, inclusions, and cracks that are present at all practical length scales (Becker, 2011).

To establish an accurate representation of as-manufactured mechanical, physical, and thermal properties in nuclear-grade graphites, data that captures the level of variation in measured values must be comprehensively captured. In a departure from the traditional deterministic method for the American Society of Mechanical Engineers (ASME) codification of materials for nuclear use, the ASME design code for graphite core materials will be a risk-based probabilistic approach (Burchell, 2007) and require requisite strength values to be described in terms of representative fracture statistics. These types of 
representative distributions are also critical for accurate stochastic modeling strategies, as a detailed finite element configuration relies upon fine meshes with the associated variation in properties being captured when defining the individual elements (Arregui-Mena, 2015). Qualifying componentry for nuclear applications that are dependent upon a representative distribution of property values require a detailed description of the expected variability, which may include intra-billet, inter-billet, and lot-to-lot variations within the grades of graphite chosen as core structural materials.

A comprehensive effort is underway to capture and quantify the baseline, or unirradiated, physical and mechanical property values of these candidate nuclear grades to validate measured values with respect to the inherent level of statistical variability. A proper capture of the raw material variability in an unirradiated state will provide crucial supplementary resolution to the limited amount of available data on irradiated candidate grades. Additionally, the baseline physical and mechanical material properties for each graphite type are critical in establishing accurate predictive thermal and mechanical models of the graphite core. Since material properties are expected to vary throughout the relatively large graphite billets in an as-produced condition, mapping the magnitude of grade-based variability, and eventually detailed spatial variability, is instrumental. In the latter case, subset variability is enabled through a dedicated protocol with regard to careful tracking of individual specimen source, position, and orientation information such that comparisons can be made with regard to properties between different lots, billets, and positions within a single billet.

The specific comparisons being made in this work are based upon the five major candidate grades being evaluated for VHTR designs and irradiated in a concurrent set of experiments known as the Advanced Graphite Creep program (Gibbs, 2007). These grades also provide a spread in the vendorspecific raw material and processing techniques as characterized by raw material source, filler particle size, and compaction method. A summary overview of the evaluated grades, drawn from the associated program plan summary (Burchell, 2007) and readily available catalog information from individual vendors, is shown in Table 1. 
This paper presents broad comparisons by individual graphite grade and clarifies an effective means for representing those distributions. While future analyses will provide more detailed discussions on actual spatial variability and orientation effects within individual billets or across lots of the same grade, the data sets being focused on in this work are generally pooled entirely by grade. Grade-based data is the most beneficial comparator to the limited irradiated property data, which is also evaluated by grade, as data subsets large enough to capture inter-billet position or orientation would expand irradiation programs to economically impractical levels. While a snapshot of the type of spatial variability that will become available as larger data populations are compiled is provided in this paper as an illustrative example, the focus is on uncensored data representative of specific grades without breakdowns by spatial position or orientation. These grade-based distributions are intended to provide an introductory overview of the variability in the candidate grades and an initial comparison of property distributions. The property data is generated from three full-size billets of NBG-18 and PCEA, a single full billet of NBG-17 and 2114, and two partial billets of IG-110, totaling to more than 5000 specimens. The ensuing comparisons include both nondestructive analyses to ascertain selected physical properties along with uniaxial mechanical strength property values.

One common method for illustrating statistical distributions of data is the cumulative distribution function $F(x)$ developed by Weibull (Weibull, 1951) that takes the following form:

$$
F(x)=1-e^{-\left(\frac{x}{\beta}\right)^{m}}
$$

In this two-parameter relationship, $x$ is the individual measured property, $\beta$ is the associated scale parameter below which $63.2 \%$ of the values from the measured data set fall, and $m$ is the shape parameter describing the slope of the cumulative function. When applied specifically to strength values, the shape parameter $m$ is also commonly referred to as the Weibull modulus, while the scale parameter, being indicative of the representative magnitude of the value being measured in the cumulative distribution, is also referred to as the characteristic value. As a means to illustrate both the two-parameter Weibull distribution and the approach for grade-based pooling of data, Fig. 1 (Carroll, 2013) demonstrates the 
distributions for tensile strength as measured from three individual billets of NBG-18 without regard to position or orientation. The individual distributions do not vary significantly in shape or characteristic value, and thus the overall distribution of tensile strength values superimposed on the individual distributions can be regarded as a representative distribution of strength values for this grade. The two-parameter Weibull distribution, such as that introduced in Fig. 1, is presently the only statistical analysis technique specifically adopted as an ASTM standard (ASTM D7846-12) for the evaluation of graphite mechanical properties. While further data collection and dissemination will continue to evaluate the merits of other distribution types to provide the most accurate model for property distribution probabilities, the Weibull distribution is currently the primary tool for presenting data sets side by side for comparison. The approach has a sound basis in historical graphite studies; the comprehensive data mining (Nemeth, 2013) performed on published H-451 graphite properties (Price, 1976) indicated that the twoparameter Weibull distribution provided a very good approximation for pooled data sets. That particular effort, while limited to specimens from a single billet of the extruded grade $\mathrm{H}-451$, was further corroborated by research on vibration-molded NBG-18 (Hindley, 2012). The limited data populations either previously reported or described in the ASTM standard provide an opportunity for accurate gradebased distributions to be generated that (1) are not limited to small sample sets and (2) provide a basis for truncated data sets to be directly compared to a fully representative set of property values to ascertain corroborations or differences in measured properties. Examples of truncated data sets include those collected during irradiation experiments and subsequent property measurements or the qualification of existing grades that are produced from raw materials sources that are geologic in nature and may harbor inherent inconsistencies.

\section{Experimental Procedures}

The physical and mechanical properties were generated based upon a systematic evaluation of specimens in accordance with the applicable ASTM International standard, while tracking the grade, 
position, and orientation of each individual specimen (Carroll, 2010). Tensile testing is carried out via ASTM C749-08, flexural testing via ASTM C651-11, and compressive testing via ASTM C695-91. The relatively simple shapes of flexural (rectangular bars) and compressive specimens (right circular cylinders) also render them ideal for the non-destructive evaluation of elastic material constants, such as dynamic Young's modulus obtained through measurements of resonant frequency (ASTM C747-93) or sonic velocity (ASTM C769-09). Additionally, the respective specimen geometries also allow accurate and relatively straightforward dimensional and volume measurements, facilitating the collection of density values per ASTM C559-90. Each of these non-destructive evaluations is performed on specimens prior to mechanical testing. As described in the introductory section, the goals of the overall program necessitate the accurate tracking of individual specimen source, position, and orientation information, but the grade-specific focus of this particular paper does not delve into detail on spatial or orientation-based information.

Individual sectioning plans were subject to some level of variability in the number of tensile, flexural, or compressive specimens produced based on relative geometries and a random sampling of sub-blocks within each billet. The NBG-18 billets generally yielded 580-770 total specimens, PCEA yielded 450600 specimens, NBG-17 yielded 600-760 specimens, and 2114 yielded 760-840 total specimens per full-sized billet. The first billet of IG-110 under evaluation was a partial billet and only 142 specimens were machined and tested.

The Weibull approximation described previously is utilized to present the property data as cumulative distribution functions as it presents the most precise fit to the large pooled data sets presented herein regardless of the grade of graphite. Comparisons between the different distribution functions that rely upon the Anderson-Darling "goodness of fit" parameter as a distribution qualifier, readily obtainable through Minitab ${ }^{\mathrm{TM}}$ evaluation tools, indicate that the Weibull distribution provides the best representation. Rather than rely upon an evaluative approach whereby theories on fundamental mechanisms predict the proper fit of data distributions, the large data sets collected on the candidate graphite grades allow a number of different distributions to be directly compared. The number of specimens in each population, $n$, 
varies between grades and will likely remain proportionally similar even as the data sets expand. From a data population standpoint, the number of specimens in a distribution is directly related to the confidence bands that are associated with a particular distribution. In this case, 95\% confidence bands are visible in each of the graphical representations. With a program strategy focused on collecting an amount of data that greatly exceeds the number required to effectively limit the range of any particular confidence band, the amount of data collected is driven more by the presence of identifiable outliers. Grades that exhibit a larger fraction of outlying values, particularly at the lower property value end of the distribution, are naturally going to be a priority with regard to the collection of further data and ultimate sample population size.

\section{Material Property Comparisons}

\subsection{Physical Properties}

Per the ASTM International standard, graphite has a minimum allowable density of $1.7 \mathrm{~g} / \mathrm{cc}$ to be considered nuclear-grade (ASTM D7219-08). The vast majority of the measured densities fall within this range, as illustrated in Fig. 2(a). Outside of the relationship to core power analyses and ultimate operational predictability based on core neutronics, density is not considered a performance property. It is, however, a reasonably accurate predictor of the variation in other physical and mechanical properties, so trends in density distributions and comparisons with other properties are an effective preliminary evaluation of the quality of individual test specimens.

In the longitudinal (flexure) mode, the resonant frequency of vibration from impulse excitation of rectangular flexure bars is indicative of the elastic modulus or dynamic Young's modulus, $E_{d y m}$, shown in Fig. 2(b). The general relationships between grades exhibited by the modulus measurements are similar to those of the density distributions. NBG-18, for example, has both the highest density and highest overall elastic modulus values as represented by the respective scale parameters, while IG-110 has the lowest values in both measured properties. Table 2 provides a compilation of the $E_{d y m}$ values for each of the candidate grades, illustrated through Weibull-based scale $(\beta)$ and shape $(m)$ parameters which, in a two- 
parameter distribution, can be directly compared. However, the tail ends of the PCEA curve and associated data points result in this grade having the lowest values in the area of the cumulative distribution that falls below $1 \%$.

The grade-specific consistency between density and $E_{d y m}$ distributions is not entirely surprising, as the calculation for modulus (ASTM E1876-09) takes specimen dimensions and mass into account, and so the resulting values are directly linked via the relationship

$E_{d y m}=0.9465\left(\frac{m f_{f}^{2}}{b}\right)\left(\frac{L^{3}}{t^{3}}\right) T_{1}$

where $E_{d y m}$ is the dynamic Young's modulus, $m$ is the mass of the bar, $f_{f}$ is the measured fundamental frequency in flexure, $b, L$ and $t$ are the width, length, and thickness of the bar, respectively, and $T_{1}$ is a correction factor for fundamental flexural mode. As the mass is included in the calculation and the dimensional terms follow a strict ratio between specimens of different grades, the density value is directly related to the dynamic Young's modulus. Revealed in a comparison between the two distributions, however, is that the relative offset of the distributions from the two different measurement data sets are not consistent between the different grades. In other words, the distributions do not show a consistent scalar shift based strictly upon the remaining fixed values in the equation. Therefore, this differing shift in values is a product of the varying resonant frequencies being measured, along with the resulting divergent behavior in calculated elastic moduli. The lack of direct proportionality in the Weibull distributions of the density and elastic modulus provide an indication of the role of other physical characteristics on dynamic Young's modulus values, including the general configuration of the microstructure in terms of defect population. This inferred microstructural role will be explored further in the Discussion section.

Additionally, measured fundamental frequencies through impulses that result in torsional vibrations provide dynamic shear modulus values, although the data is not shown based upon the similarity in its trends relative to the modulus and density data already presented. Just as with the density and dynamic Young's modulus property distributions, the extruded PCEA graphite has the highest level of variability 
(lowest shape parameter), while NBG-18 and IG-110 show the highest and lowest characteristic values, respectively.

\subsection{Compressive Testing}

A comparison of the compressive strengths of individual specimens between the five candidate billets of graphite is shown in Fig. 3. Table 3 provides a compilation of the strength values for each of the candidate grades represented by Weibull-based scale $(\beta)$ and shape $(m)$ parameters. A considerably wider distribution in measured compressive strength is seen in the extruded graphite (PCEA) compared with the molded graphites, while the highest overall compressive strength is exhibited by the fine-grained isomolded grade 2114. The extruded PCEA exhibits the largest range in strength values and also the lowest characteristic compressive strengths, although the measured strength is not solely determined by the grain size or formation technique. The fine-grained and isomolded IG-110 graphite has a much lower range of compressive strength values than the similarly fine-grained and isomolded grade 2114 , further suggesting an influence from factors other than grain size or compaction method.

What is certainly consistent between the two fine-grained isomolded grades is that the variability is significantly lower than that of other grades; the highest Weibull modulus values are exhibited by 2114 and IG-110, at 23.92 and 24.30, respectively. IG-110 also exhibits an inflection in the representative distribution at the lower compressive strength values that results in a section of the distribution with a much higher slope, indicative of comparatively high consistency in compressive strengths even at the lowest values. Contrast the shape of this strength distribution to that of NBG-17, which, for the specimens tested, exhibits an opposite inflection in distribution slope at the lower end. The flattened and diffuse shape of the low end of the NBG-17 distribution is characteristic of a number of specimens failing at much lower values than would be predicted by the Weibull approximation, which is likely due to some distribution of atypical internal flaws that result in failure at lower stresses but are not inherent to the entire specimen population. The IG-110 and NBG-17 examples given are in contrast to NBG-18 and 2114, which possess relatively consistent log-log slopes - indicative of a level of strength consistency that 
is well represented by the two-parameter cumulative function and strength values that do not drift into lower outlier values at the low end of the distribution.

With regard to compressive deformation, Fig. 4 shows the amount of compressive strain prior to failure in each of the grades. As the elastic modulus values suggest, the IG-110 requires the lowest levels of applied stress for a given amount of elastic or pseudo-plastic deformation. The ability to maintain its integrity through a higher level of deformation is an indication of the cumulative and relatively homogenous nature of fracture in the graphite. The lesser amount of deformation at failure in the other grades is an indication that, on relative terms, the limiting critical flaw leads to a more rapid onset of crack instability as a localized stress limit is exceeded.

\subsection{Flexural Testing}

The distributions of measured flexural strength for the candidate grades are shown in Fig. 5 and are quantified in Table 3. Again, the extruded medium-grain PCEA has the highest level of variability in the measured data. The fine-grained isomolded grades of graphite, 2114 and IG-110, demonstrate the highest level of strength in flexure, while the medium-grained NBG-17 exhibits slightly higher flexural strength than its larger-grained vibrationally molded counterpart, NBG-18. Graphites 2114 and IG-110 show flexure strength characteristic values of over 41.3 and 36.6 MPa, respectively; NBG-18's characteristic value is the lowest at just over 28.4 MPa. ASTM D7219 provides minimum values for flexure strength that vary considerably based upon the formation technique and relative purity of the graphite. For the isomolded graphite, this value is $35 \mathrm{MPa}$, while extruded and molded (including vibration-molded) grades require strength levels greater than $21 \mathrm{MPa}$. The characteristic values are all above the required values for each of the candidate grades.

Testing in flexure subjects the flexure bars to a highest applied stress state between the two load rollers at the outer (lower) surface of the specimen under load. The flaw distribution leading to fracture is therefore provided a limited amount of volume subjected to the highest stress levels, and will naturally exhibit higher strength at failure values. The finest-grained specimens are likely populated by flaw distributions that are homogeneous within the stressed volume, resulting in a high Weibull modulus value 
and elevated strength levels. By contrast, the less homogeneous extruded graphite has a widespread distribution of flaws, evident from the lower measured strength levels and a lower calculated Weibull modulus. The lower Weibull modulus value is indicative of a larger number of specimens with critical flaws that are captured in the high-stress regions, resulting in reduced relative strength levels. Those specimens that do not have critical or otherwise limiting flaws in the volume under the highest stress exhibit strength values that are higher in magnitude in the upper range of the data distribution. The flexural strength results suggest that the extruded graphite grade has a higher distribution of critical flaws, as evidenced by lower Weibull modulus values and lower measured strength values, than either the vibrationally molded or isomolded grades.

\subsection{Tensile Testing}

The quantitative comparison of tensile strength distributions between the candidate graphites is shown in Fig. 6 with parameter values also listed in Table 3. As with the other mechanical test values, the trend in uniaxial tensile properties indicates that a wider distribution exists in measured values for the only extruded grade tested, and the tightest relative distributions, or $m$ values, are exhibited by the fine-grained grades. The highest strength levels, similar to flexural strength results, are also exhibited by the fine-grained grades. With scale parameter values ranging between 18.5 and $20.4 \mathrm{MPa}$ for the extruded/vibration molded grades and 25.5 and $30.6 \mathrm{MPa}$ for the isomolded grades, all characteristic strengths exceeded the minimum designated strength levels required by ASTM D7219, at $15 \mathrm{MPa}$ for extruded or vibration molded grades and $22 \mathrm{MPa}$ for isostatically molded grades.

\section{Discussion}

\subsection{Measured Property Variability}

With regard to measured strength values, pooling the data sets by grade and comparing both shape and scale parameters offers an opportunity to consider the deformation resistance and ultimate failure mechanisms from a bulk scale rather than a micro- or macro-mechanistic scale. The observed results for mechanical strength indicate that grain size does have an effect on strength values for graphites 
of relatively equal density, with the grades consisting of very fine grain size exhibiting the highest level of strength in tension. As the bulk product still contains filler grains that are roughly equivalent to the raw material particles used in manufacture, the compaction process will naturally result in flaw populations on the original scale of the filler particles. Variation in Weibull shape parameters between grades indicates that the flaw size and resultant effect on fracture strength is not entirely consistent, which is reasonably well explained by the variation in compaction approaches. It is clear that extrusion provides the largest disparity in limiting flaw population size, with an associated propensity for outlying strength values that vary considerably from the $95 \%$ confidence bands at the low end of the stress range. The effect cannot easily be attributed to grain size, as the shape parameter values for vibration molded NBG-17 are much closer to the larger-grained NBG-18 than the extruded PCEA. The fine-grained grades IG-110 and 2114 exhibit the highest tension-based strength values along with the highest relative Weibull shape parameters. The elevated shape parameter values that remain consistent even to the lowest extrema provide an indication of the consistency of the limiting flaw sizes in the finer isomolded grades.

Interestingly, the IG-110 does not exhibit similarly high levels of strength in compression, providing an opportunity to consider the bulk effect of overall density on deformation in compression. One component of compressive deformation is the collapse of existing void space in the microstructure and the associated stress from loading concentrating at the microscale in surrounding material. As graphite is a granular material, failure in compression will also have an adhesion component between bound particles that resist compressive displacement. This adhesive shear resistance will, like the tensile response, be directly affected by limiting flaw populations in regions of concentrated stress. Between the contributing effects of void collapse and flaw distributions, the comparisons of compressive strength are illustrative of the density component exhibited by the proportionally lower compressive strength seen in IG-110 as well as the limiting flaw component resulting in the lowest overall shape and scale parameters exhibited by the extruded PCEA.

Representing the properties of individual graphite grades by fully pooled data sets also provides an opportunity to examine the utility of the present minimum-value criteria prescribed in international 
standards as acceptance standards for nuclear-grade graphite. The presented test results provide comparisons of scale parameters with those prescribed minimum values, but utilizing comprehensive data sets and adopting the most representative distribution potentially enables the establishment of acceptable property values defined by descriptive property distribution parameters. Based on the clear differences in both shape and scale parameters described by Weibull distributions, an acceptance approach that provides prescriptive values for those parameters rather than scalar minimum values has significant merit.

The additional utility of leveraging comprehensive data sets that accurately define a representative distribution lies in the ability to provide comparative data for limited data sets. As previously described, the ability to qualify materials for nuclear applications requires a detailed and multiscale understanding of irradiated response. With the variability seen in graphite, measured properties in irradiated specimens will not likely capture sufficient data to fully account for this inherent variability when attempting to define a distribution through descriptive shape and scale parameters. Direct comparison with known distributions provides an enhanced ability to transpose a known level of variability onto limited data sets, increasing the confidence in anticipated property distributions in components and enabling more representative reliability estimates. Proposed reliability analyses for nuclear component acceptance of graphite components, such as the approach described by Duffy et al. (Duffy, 2014), demonstrate the importance of distributions for determining, from a statistical standpoint, whether acceptance criteria is met. The ability to contract the confidence bands for specific property distributions based on an understanding of actual graphite response would enhance the application of this approach in determining probabilities of failure.

Accurate data distributions can also facilitate the acceptance of graphite as a raw material through the application of a baseline distribution with which future lots of the same graphite grades can be compared. Rather than relying on unweighted statistical approaches for determining the confidence bands of un-corroborated distributions, sampling plans for lots or billets can be based upon established shape and scale parameters to determine whether future lots of the same theoretical grade fall into the known distribution. The requisite population size could be smaller for the fine-grained isomolded grades than for 
other grades using alternate means of compaction, whereas capturing a representative data set for the qualification of an extruded grade would require a broader sampling plan.

\subsection{Spatial Representation of Anomalous Data}

Aside from the broad pooling of data sets by grade, an analysis of the Weibull distributions being generated and the resultant scale parameters provide insight into grades that require further scrutiny from a property distribution standpoint. Using the extruded grade (PCEA) as the prime example, discussion has focused on the apparent effect of inherent flaw distribution on observed data variability. One of the real benefits of the Weibull distribution, as an accurate depiction of property distributions, is that it is an extreme-value distribution. From a reliability analysis standpoint, the extreme values of interest are those that define the cumulative function at the lowest property values, particularly when those values exhibit a convex inflection at the low end of the distribution. Such values and the resulting shape indicate a population of strength-limiting flaws outside of the Weibull-defined distribution. These so-called disparate flaws, defined in early graphite research as flaws on a size scale that exceeds the graphite filler particle size (Kennedy, 1986), can lead to low outliers in measured strength data points. In such cases, the analysis of disparate flaws and the underlying factors for their distributions benefit from resolving spatial patterns or inconsistencies in the grades under investigation. Fig. 7 shows the same density values plotted for PCEA in Fig. 2(a) meshed together from three billets in a three-dimensional representation. While this spatial relationship could not be ascertained from the pooled Weibull distribution, the change in density from the upper outside to the lower inside of the representative billet is clear from the cumulative number of density measurements taken from compressive and flexural specimens. In a similar manner, preexisting disparate flaws can be plotted from specimens that never made it to the testing stage as a result of the type of larger-scale voids seen in Fig. 8. Fig. 9 shows the cumulative individual positions in cylindrical extruded billets from which test specimens were not able to be fully machined due to failure during the handling/extraction/machining process. This rather extreme example of a disparate flaw, attributable to manufacturing process control factors, has been seen in several billets of graphite from different grades. While this type of flaw is at the extreme end of the length scale with regard to the overall 
flaw population, flaws on length scales that approach the effective test specimen gauge length can also result in pre-test failure and effective zero-strength values. By pooling the recorded position of all zerostrength or specimens that failed during machining and comparing the pooled spatial representations in Figs. 7 and 9, these larger disparate flaws that compromise the ability to test the properties at a given billet position are grouped in the same region as the finished specimens with the lowest density values. As density tends to track with strength values within a specific grade, it can be inferred that the regions depicted on a three-dimensional property map provide less of a margin to the reliability limit for components extracted from those sections, even in the absence of a large enough subset of strength data to stand alone in providing an accurate reliability assessment. The coupling of both spatially resolved grade property data and pooled grade-based data provides an enhanced ability to increase the resolution of evaluated parameters. Further reliability analyses could then naturally focus on pooling subsets of data from specific sections of billets within a particular grade, underscoring the value of specimen position and orientation tracking. The observance of inconsistencies or multi-modal distributions in the pooled data sets can similarly provide an impetus for further breaking down pooled data into logical subsets, such as by orientation or general spatial locations. From a manufacturing perspective, knowledge of specific clustering of properties or flaws provides an opportunity to improve manufacturing processes to increase homegeneity — an effect that will be evident from higher shape parameters in subsequent Weibull property distributions.

\subsection{Micro-mechanistic Analyses Facilitated by Pooled Data Sets}

The differences in distributions and relative scale values across the different grades also provide an opportunity to compare the micro-level interactions between different graphites. While the pooled data sets for a single property do not provide an adequate means to quantify microstructural mechanisms, comparisons between relative distributions allow an evaluation of these mechanisms based upon the length scale of the mechanisms behind the property measurement. An analysis of the shape and scale parameters associated with different Young's modulus measurement techniques provides such an example. While the resonant frequency technique is an effective means for measuring the elastic response 
due to impulse excitation, a more direct measurement of the relationship between stress and strain is recorded with each tensile test.

The Young's modulus, $E$, is the ratio between the stress applied by the load frame and the strain measured with an attached extensometer captured during tensile testing via the relationship $E=\sigma / \varepsilon$. Quantifying the proportional stress-strain response in graphite is not entirely straightforward, however, owing to the decidedly non-linear stress versus strain trace as load is applied. An example of this behavior, consistent in all grades of graphite (Kennedy, 1987), is shown in Fig. 10, along with the approach utilized here by which the slope of the tangent to the initial stress-strain curve provides the measured modulus values. The minimum actual curvature, or portion of the curve having the most "linear" response, is in the earliest stage of strain accumulation. The tangent to this region of the curve provides the most representative estimate of bulk-based elastic modulus. Fig. 11 shows plots of the differences in both shape and scale parameters between modulus measurements for NBG-18 and PCEA using three different techniques, each based on bond interactions within the microstructure that combine at different length scales to provide a measured value.

As Fig. 11 illustrates, an upward shift in modulus values is exhibited in varying magnitudes across each of the graphite grades from the values measured by stress/strain tests to resonant frequency to that calculated via sonic velocity. The modulus measured during tensile testing is based upon bonds cumulatively stretching throughout the entire volume of the gauge section. Resonant frequency testing is based on the constructive interference between planar shock waves that propagate in a manner consistent with the elasticity in the atomic bonds of the graphite being tested, while modulus testing based upon the minimum amount of interactive bond stretching at any given moment of the measurement - that acquired through the measure of sonic velocity, which is based upon a single planar sound wave - exhibits the highest characteristic value, $\beta$, for measured elastic modulus values. The shape parameter, $m$, is also considerably higher for sonic velocity measurements, indicating the reduced effect of flaw populations on the parameters being measured using this approach. 
As can be ascertained from the distributions in Fig. 11, the difference in the distributions of the modulus values measured using each of the techniques are not offset from one another by a consistent amount between each of the candidate grades. This behavior provides an additional means by which to quantify characteristics at the grain/filler particle/microvoid size scale to further investigate governing deformation mechanisms in bulk properties. This is of considerable importance to the development of mechanistic models that utilize microstructure-based relationships as an important component when describing and predicting the performance of nuclear-grade graphites.

\section{Summary}

The comparative strength, density, and elastic property distributions of each candidate grade of graphite, NBG-18, NBG-17, PCEA, IG-110, and 2114, have been compiled. The property values have been tracked by billet and billet location for 5,000 specimens and are optimally represented by the extreme-value nature of the Weibull distribution. Flexure and tensile characteristic strength values are higher for the finer-grained isomolded grades than for the extruded or vibration-molded grades. The extruded grade almost universally exhibits a larger variability in measured values, underscoring the necessity for additional billets to be tested from separate lots when determining the qualification criteria for extruded graphite.

This large-scale collection of data enables accurate physical and mechanical property distributions and increases the understanding of the inherent grade-based variability that should be present in irradiated specimens evaluated from the same grades. The relative relationships between the grades being compared are represented by a sufficient data population to draw general conclusions about overall property/distribution differences and to acknowledge the utility of appropriate cumulative distributions to describe property values. The characteristic value and shape parameter may be either compared individually as pooled data sets by grade or combined with other distributions to provide clarity on spatial differences or relative micro-mechanistic response mechanisms. 
This work suggests that the practice of designating a minimum property value for nuclear-grade graphites without regard for the overall distribution characteristics is not optimal or sufficiently prescriptive. Evaluations requiring a minimum number of specimens, designated based on grain size and compaction techniques, are a clear necessity. Furthermore, capturing the shape and scale parameters that identify required graphite properties based on Weibull cumulative distribution functions is a more instructive means of enveloping graphite performance as a structural material in modern reactors.

\section{Acknowledgements}

This study was carried out under Contract DE-AC07-05ID14517 with the U.S. Department of Energy Office of Nuclear Energy. Accordingly, the U.S. Government retains a non-exclusive, royalty-free license to publish or reproduce the published form of this contribution, or allow others to do so, for U.S.

Government purposes.

\section{References}

Allen, T. R., et al., 2008. Materials Challenges for Generation IV Nuclear Energy Systems. Nuclear Technology 162, 342-357.

U.S. Department of Energy Nuclear Energy Research Advisory Committee and the Generation IV International Forum, 2002. A Technology Roadmap for Generation IV Nuclear Energy Systems, 2002. 03-GA50034.

Hindley, P., et al., 2013. A numerical stress based approach for predicting failure in NBG-18 nuclear graphite components with verification problems. Journal of Nuclear Materials 436, 175-184.

Nemeth, N. N. and R. L. Bratton, 2010. Overview of statistical models of fracture for nonirradiated nuclear-graphite components. Nuc. Eng. Des. 240, 1-29.

Becker, T., et al., 2011. Damage, crack growth and fracture characteristics of nuclear grade graphite using the double torsion technique. Journal of Nuclear Materials 414, 32-43.

Burchell, T. D., et al., 2007. NGNP Graphite Selection and Acquisition Strategy, ORNL/TM-2007/153, Oak Ridge, TN.

Arregui-Mena, J. D., et al. 2015. Spatial variability in the coefficient of thermal expansion induses preservice stresses in computer models of virgin Gilsocarbon bricks. Journal of Nuclear Materials 465, 793-804. 
Gibbs, G. A. (approver), 2011. NGNP Project: 2011 Status and Path Forward, INL/EXT-11-23907, Idaho National Laboratory, Idaho Falls, ID.

ASTM C749-08, 2010. Standard Test Method for Tensile Stress-Strain of Carbon and Graphite, ASTM International, West Conshohocken, PA.

ASTM C651-11, 2011. Standard Test Method for Flexural Strength of Manufactured Carbon and Graphite Articles Using Four-Point Loading at Room Temperature, ASTM International, West Conshohocken, PA.

ASTM C695-91, 2010. Standard Test Method for Compressive Strength of Carbon and Graphite, ASTM International, West Conshohocken, PA.

ASTM C747-93, 2010. Standard Test Method for Moduli of Elasticity and Fundamental Frequencies of Carbon and Graphite Materials by Sonic Resonance, ASTM International, West Conshohocken, PA.

ASTM C769-09, 2009. Standard Test Method for Sonic Velocity in Manufactured Carbon and Graphite Materials for Use in Obtaining Young's Modulus, ASTM International, West Conshohocken, PA.

ASTM C559-90, 2010. Standard Test Method for Bulk Density by Physical Measurements of Manufactured Carbon and Graphite Articles, ASTM International, West Conshohocken, PA.

Carroll, M. C., et al., 2010. Baseline Graphite Characterization: First Billet, INL/EXT-10-19910, Idaho National Laboratory, Idaho Falls, ID.

Weibull, W., 1951. A statistical distribution of wide applicability. J. Appl. Mech. 18, 293-297.

Carroll, M. C., 2013. VHTR R\&D Technical Review Meeting, Idaho Falls, Idaho.

ASTM D7846-12, 2012. Standard Practice for Reporting Uniaxial Strength Data and Estimating Weibull Distribution Parameters for Advanced Graphites, ASTM International, West Conshohocken, PA.

Nemeth, N. N., et al., 2013. Large-scale Weibull analysis of H-451 nuclear-grade graphite rupture strength. Carbon, 58, 208-225.

Price, R. J., 1976. A statistical study on the strength of near-isotropic graphite. General Atomics Project 3224, GA-A13955 and UC-77.

Hindley, M. P.,et al. 2012. Observations in the statistical analysis of NBG-18 nuclear graphite strength tests. Journal of Nuclear Materials 420, 110-115.

Minitab, Inc. Quality Plaza, 1829 Pine Hall Rd, State College PA 16801-3210 USA.

ASTM D7219-08, 2008. Standard Specification for Isotropic and Near-Isotropic Nuclear Graphites, ASTM International, West Conshohocken, PA.

ASTM E1876-09. Standard Test Method for Dynamic Young's Modulus, Shear Modulus, and Poisson's Ratio by Impulse Excitation of Vibration, ASTM International, West Conshohocken, PA. 
Duffy, S. F. and P. Ankurben, 2014. Quality Control Using Inferential Statistics in Weibull-Based Reliability Analyses, in: Tzelepi, A. and Carroll, M.C. (Eds.), Graphite testing for Nuclear Applications, STP 1578, ASTM International, West Conshohocken, PA, pp. 105-122.

Kennedy, C. R. and W. P. Eatherly, 1986. The statistical characterization of tensile strengths for a nuclear-type core graphite, International Nuclear graphite Specialists Meeting, Tokai, Japan.

Kennedy, C. R., 1987. Statistical Characterization of Three Grades of Large-Billet Graphites: Stackpole 2020. Union Carbide TS1792 and Toyo Tanso IG11. DOE-HGTR-87-010, ORNL/TM-10457, Oak Ridge, TN.

Carroll, M. C. and D. T. Rohrbaugh, 2013. Statistical Comparison of the Baseline Mechanical Properties of NBG-18 and PCEA Graphite, INL/EXT-13-30011, Idaho National Laboratory, Idaho Falls, ID. 


\section{Tables}

Table 1

Graphite grades and production characteristics based on advertised information available from the manufacturer.

\begin{tabular}{lllll}
\hline Grade & Manufacturer & Filler Source & Filler Particle Size & Compaction Method \\
\hline NBG-18 & SGL Group & Pitch Coke & $1.6 \mathrm{~mm}$ & Vibration Molded \\
PCEA & GrafTech & Petroleum Coke & $0.8 \mathrm{~mm}$ & Extruded \\
IG-110 & Toyo Tanso & Petroleum Coke & $20 \mu \mathrm{m}$ & Isostatically Molded \\
2114 & Mersen & Pitch Coke & $13 \mu \mathrm{m}$ & Isostatically Molded \\
NBG-17 & SGL Group & Pitch Coke & $0.8 \mathrm{~mm}$ & Vibration Molded \\
\hline
\end{tabular}

Table 2

Physical property distributions described by Weibull parameters.

\begin{tabular}{clll}
\hline Property & Grade & Scale parameter, $\beta(\mathrm{MPa})$ & Shape parameter, $m$ \\
\hline Density & & & \\
\hline & NBG-18 & 1.850 & 236.5 \\
& PCEA & 1.816 & 81.17 \\
IG-110 & 1.778 & 151.9 \\
2114 & 1.816 & 320.0 \\
& NBG-17 & 1.830 & 184.5 \\
Dynamic Young's Modulus (Resonant Frequency), $\mathrm{E}_{\mathrm{dyn}}$ & \\
\hline NBG-18 & 12.37 & 36.46 \\
& PCEA & 10.75 & 15.01 \\
IG-110 & 9.422 & 20.96 \\
2114 & 10.06 & 35.08 \\
NBG-17 & 11.29 & 43.28
\end{tabular}

Table 3

Mechanical property distributions described by Weibull parameters.

\begin{tabular}{llll}
\hline Property & Grade & Scale parameter, $\beta(\mathrm{MPa})$ & Shape parameter, $m$ \\
\hline Compressive Strength & & & \\
& NBG-18 & 82.81 & 19.54 \\
& PCEA & 67.03 & 7.01 \\
& IG-110 & 75.14 & 24.30 \\
& 2114 & 94.68 & 23.92 \\
& NBG-17 & 79.09 & 16.43 \\
Flexural Strength & & & \\
\hline & NBG-18 & 28.42 & 16.42 \\
& PCEA & 29.50 & 5.97 \\
& IG-110 & 36.55 & 13.84 \\
& 2114 & 41.30 & 18.04 \\
Tensile Strength & NBG-17 & 30.70 & \\
\hline & & & 17.97 \\
& NBG-18 & 20.40 & 3.69
\end{tabular}




$\begin{array}{lll}\text { IG-110 } & 25.54 & 12.59 \\ 2114 & 30.82 & 22.60 \\ \text { NBG-17 } & 20.01 & 12.04\end{array}$

\section{Figure Captions}

Fig 1. Three billets of NBG-18 demonstrate the relative similarity in shape and scale parameters and the result of pooling the complete data set to represent the parameters of the grade.

Fig. 2. The distributions in density values (a) and dynamic Young's modulus values calculated from resonant frequency measurements (b) reveal the lack of proportionality in the Weibull distributions, despite the density being a direct factor in the calculation.

Fig. 3. The distribution of compressive strength values for each of the candidate grades.

Fig. 4. Compressive strain distributions for the five candidate grades.

Fig. 5. The distributions of measured flexural strength values for each of the candidate grades.

Fig. 6. The distributions in tensile strength for each of the candidate grades.

Fig. 7. Pooled density values at relative positions in the billet from three extruded PCEA billets.

Fig. 8. An example of large and extended voids in one of the PCEA graphite billets that resulted in test coupon failure prior to material property testing.

Fig. 9. Recorded positions for coupon-level failure in specimens from the three extruded PCEA grade billets correlate closely with the lowest density region of the full billet.

Fig. 10. The nonlinear character of the stress-strain curves is illustrated by a complete stress-strain curve for graphite under uniaxial tension (red) and the auto-recorded Young's modulus (dashed blue).

Fig. 11. Modulus values obtained through analysis of stress-strain curves $(E)$ and through dynamic Young's modulus $\left(E_{d y m}\right)$ techniques - via sonic resonance and sonic velocity - for grades NBG-18 (a) and PCEA (b). 
Manucript: Leveraging comprehensive baseline datasets to quantify property variability in nuclear-grade graphites

\section{References}

Allen, T. R., et al., 2008. Materials Challenges for Generation IV Nuclear Energy Systems.

Nuclear Technology 162, 342-357.

U.S. Department of Energy Nuclear Energy Research Advisory Committee and the Generation IV International Forum, 2002. A Technology Roadmap for Generation IV Nuclear Energy Systems, 2002. 03-GA50034.

Hindley, P., et al., 2013. A numerical stress based approach for predicting failure in NBG-18 nuclear graphite components with verification problems. Journal of Nuclear Materials 436, 175-184.

Nemeth, N. N. and R. L. Bratton, 2010. Overview of statistical models of fracture for nonirradiated nuclear-graphite components. Nuc. Eng. Des. 240, 1-29.

Becker, T., et al., 2011. Damage, crack growth and fracture characteristics of nuclear grade graphite using the double torsion technique. Journal of Nuclear Materials 414, 32-43.

Burchell, T. D., et al., 2007. NGNP Graphite Selection and Acquisition Strategy, ORNL/TM-2007/153, Oak Ridge, TN.

Arregui-Mena, J. D., et al. 2015. Spatial variability in the coefficient of thermal expansion induses preservice stresses in computer models of virgin Gilsocarbon bricks. Journal of Nuclear Materials 465, 793-804.

Gibbs, G. A. (approver), 2011. NGNP Project: 2011 Status and Path Forward, INL/EXT-11-23907, Idaho National Laboratory, Idaho Falls, ID.

ASTM C749-08, 2010. Standard Test Method for Tensile Stress-Strain of Carbon and Graphite, ASTM International, West Conshohocken, PA.

ASTM C651-11, 2011. Standard Test Method for Flexural Strength of Manufactured Carbon and Graphite Articles Using Four-Point Loading at Room Temperature, ASTM International, West Conshohocken, PA.

ASTM C695-91, 2010. Standard Test Method for Compressive Strength of Carbon and Graphite, ASTM International, West Conshohocken, PA.

ASTM C747-93, 2010. Standard Test Method for Moduli of Elasticity and Fundamental Frequencies of Carbon and Graphite Materials by Sonic Resonance, ASTM International, West Conshohocken, PA.

ASTM C769-09, 2009. Standard Test Method for Sonic Velocity in Manufactured Carbon and Graphite Materials for Use in Obtaining Young’s Modulus, ASTM International, West Conshohocken, PA.

ASTM C559-90, 2010. Standard Test Method for Bulk Density by Physical Measurements of Manufactured Carbon and Graphite Articles, ASTM International, West Conshohocken, PA. 
Carroll, M. C., et al., 2010. Baseline Graphite Characterization: First Billet, INL/EXT-10-19910, Idaho National Laboratory, Idaho Falls, ID.

Weibull, W., 1951. A statistical distribution of wide applicability. J. Appl. Mech. 18, 293-297.

Carroll, M. C., 2013. VHTR R\&D Technical Review Meeting, Idaho Falls, Idaho.

ASTM D7846-12, 2012. Standard Practice for Reporting Uniaxial Strength Data and Estimating Weibull Distribution Parameters for Advanced Graphites, ASTM International, West Conshohocken, PA.

Nemeth, N. N., et al., 2013. Large-scale Weibull analysis of H-451 nuclear-grade graphite rupture strength. Carbon, 58, 208-225.

Price, R. J., 1976. A statistical study on the strength of near-isotropic graphite. General Atomics Project 3224, GA-A13955 and UC-77.

Hindley, M. P.,et al. 2012. Observations in the statistical analysis of NBG-18 nuclear graphite strength tests. Journal of Nuclear Materials 420, 110-115.

Minitab, Inc. Quality Plaza, 1829 Pine Hall Rd, State College PA 16801-3210 USA.

ASTM D7219-08, 2008. Standard Specification for Isotropic and Near-Isotropic Nuclear Graphites, ASTM International, West Conshohocken, PA.

ASTM E1876-09. Standard Test Method for Dynamic Young's Modulus, Shear Modulus, and Poisson's Ratio by Impulse Excitation of Vibration, ASTM International, West Conshohocken, PA.

Duffy, S. F. and P. Ankurben, 2014. Quality Control Using Inferential Statistics in Weibull-Based Reliability Analyses, in: Tzelepi, A. and Carroll, M.C. (Eds.), Graphite testing for Nuclear Applications, STP 1578, ASTM International, West Conshohocken, PA, pp. 105-122.

Kennedy, C. R. and W. P. Eatherly, 1986. The statistical characterization of tensile strengths for a nuclear-type core graphite, International Nuclear graphite Specialists Meeting, Tokai, Japan.

Kennedy, C. R., 1987. Statistical Characterization of Three Grades of Large-Billet Graphites: Stackpole 2020. Union Carbide TS1792 and Toyo Tanso IG11. DOE-HGTR-87-010, ORNL/TM-10457, Oak Ridge, TN.

Carroll, M. C. and D. T. Rohrbaugh, 2013. Statistical Comparison of the Baseline Mechanical Properties of NBG-18 and PCEA Graphite, INL/EXT-13-30011, Idaho National Laboratory, Idaho Falls, ID. 


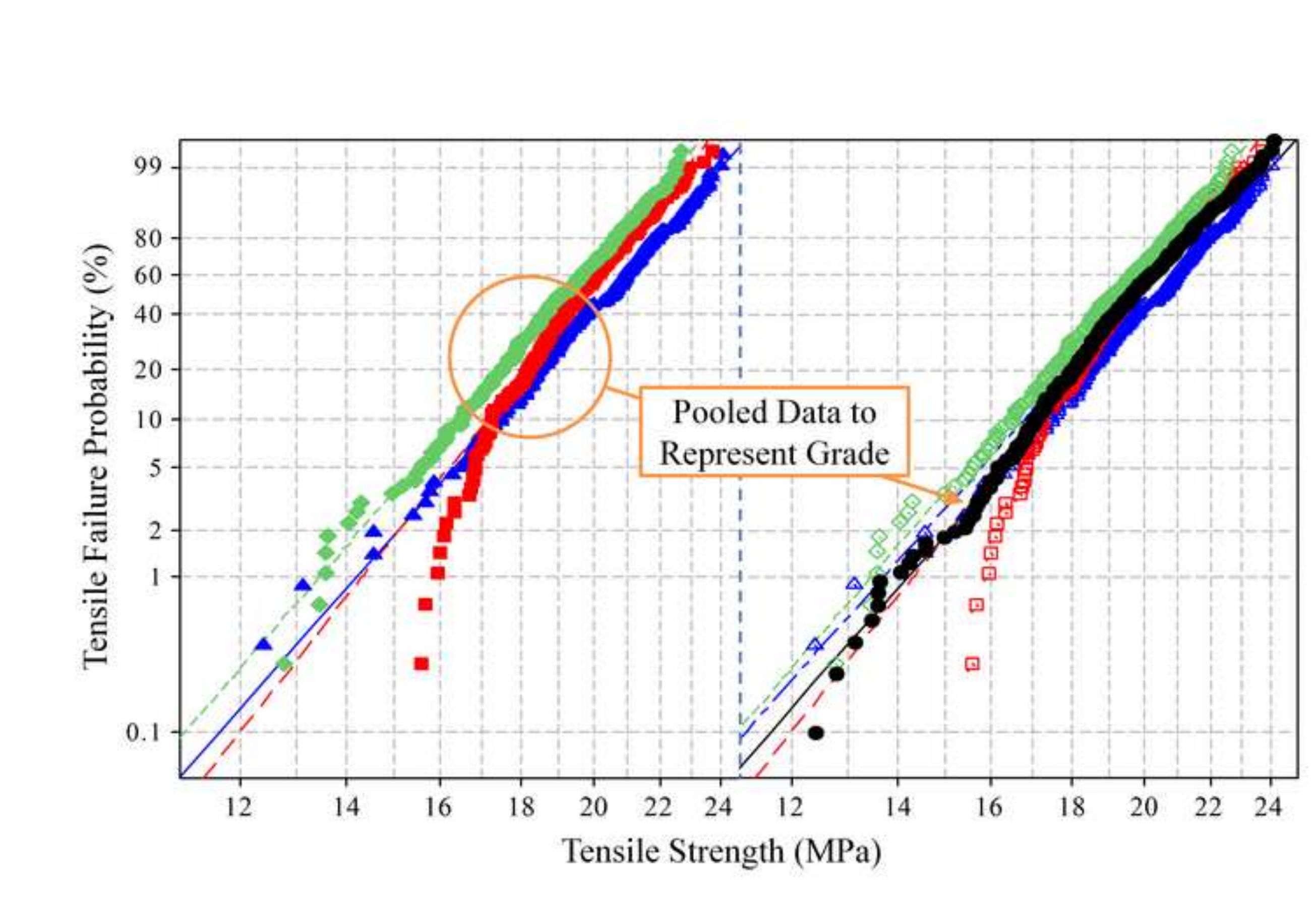

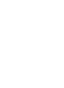




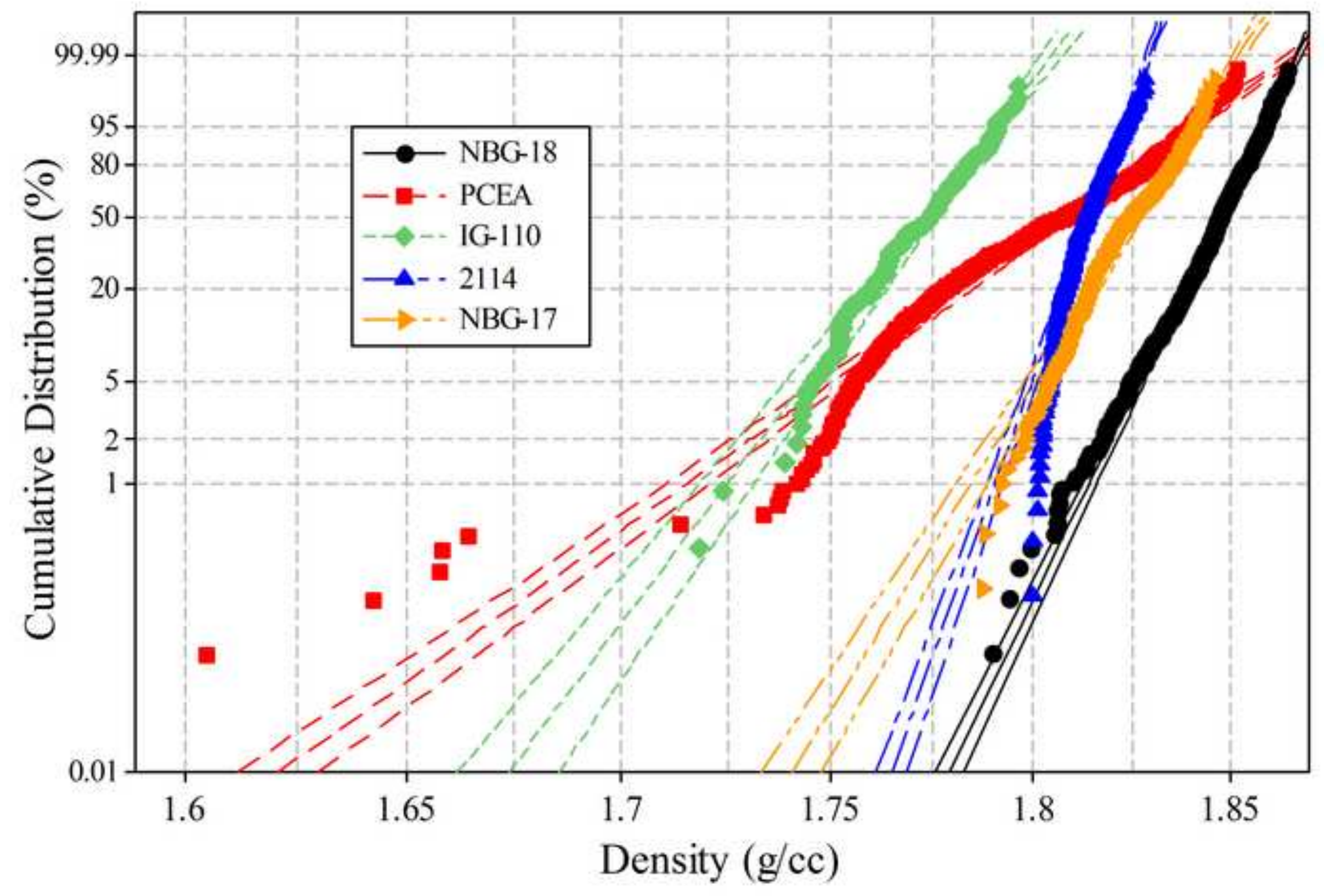




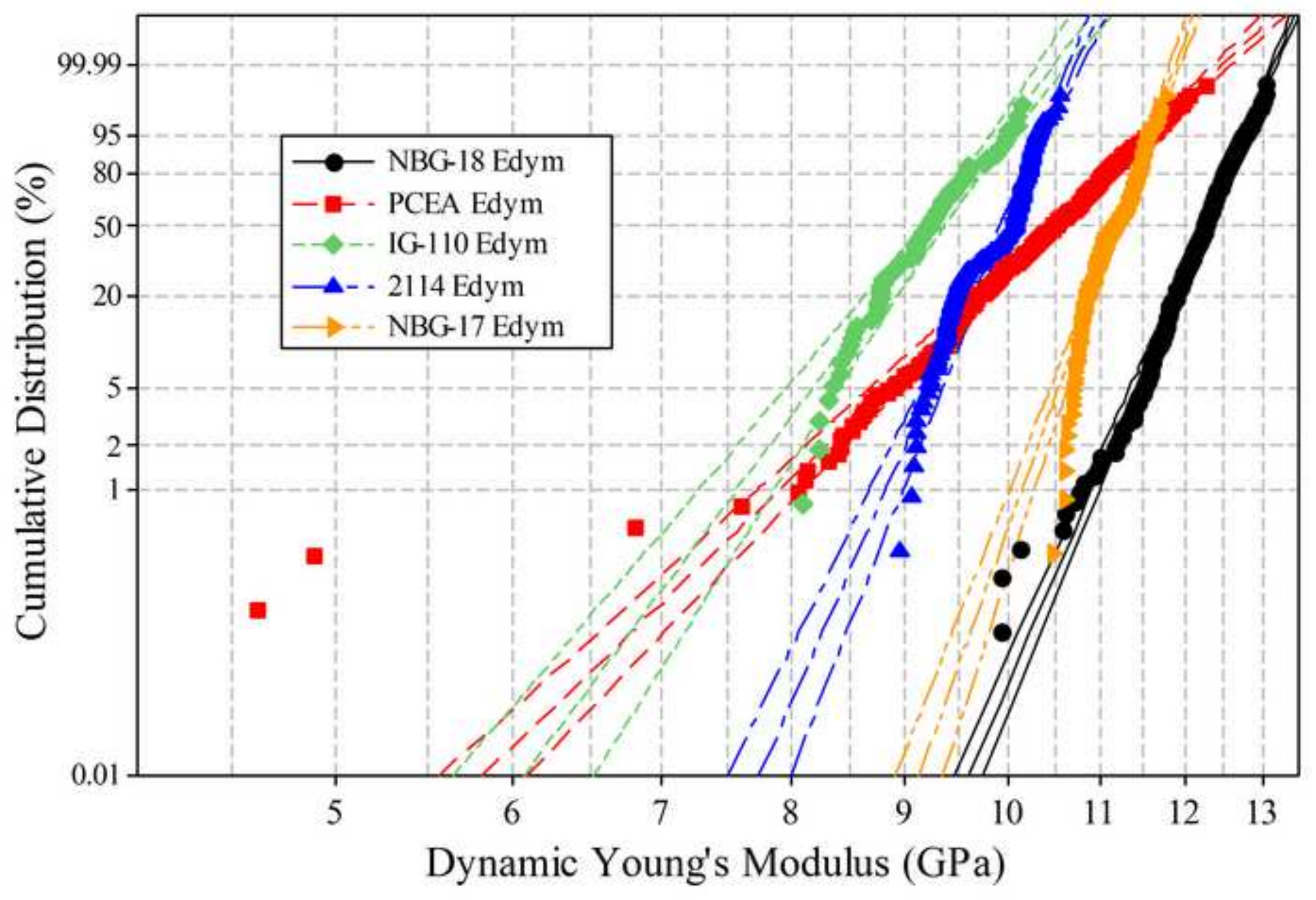




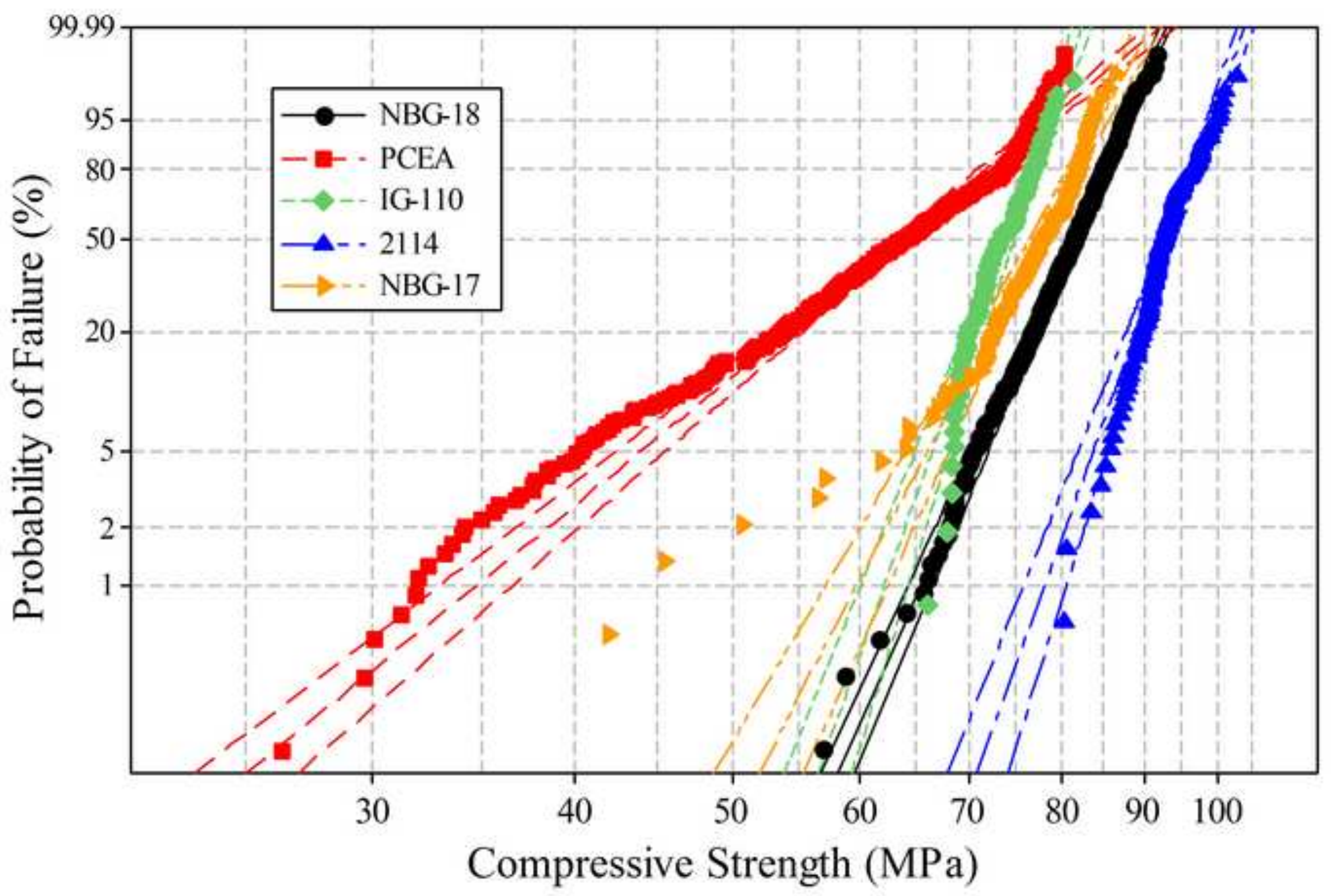




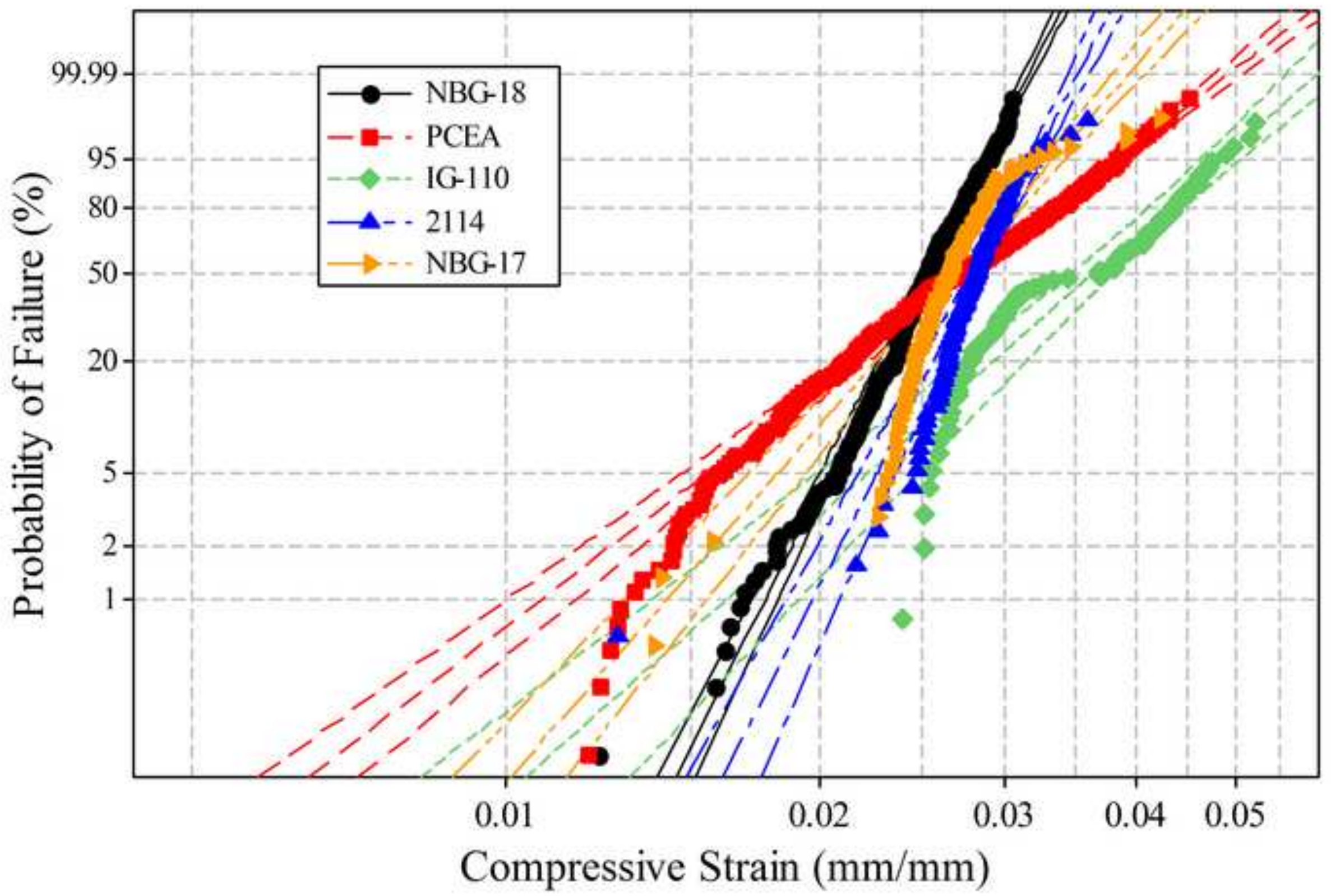




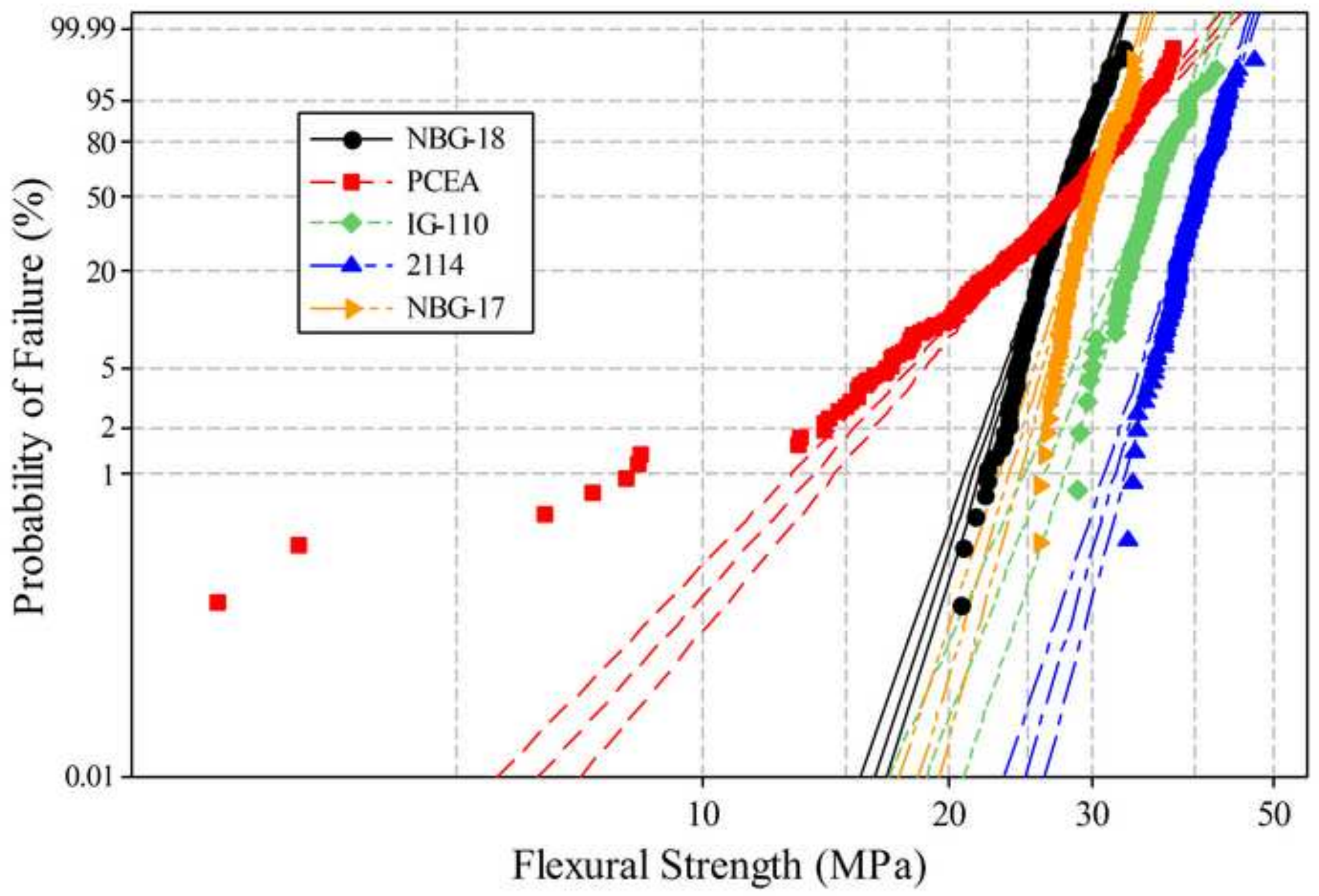




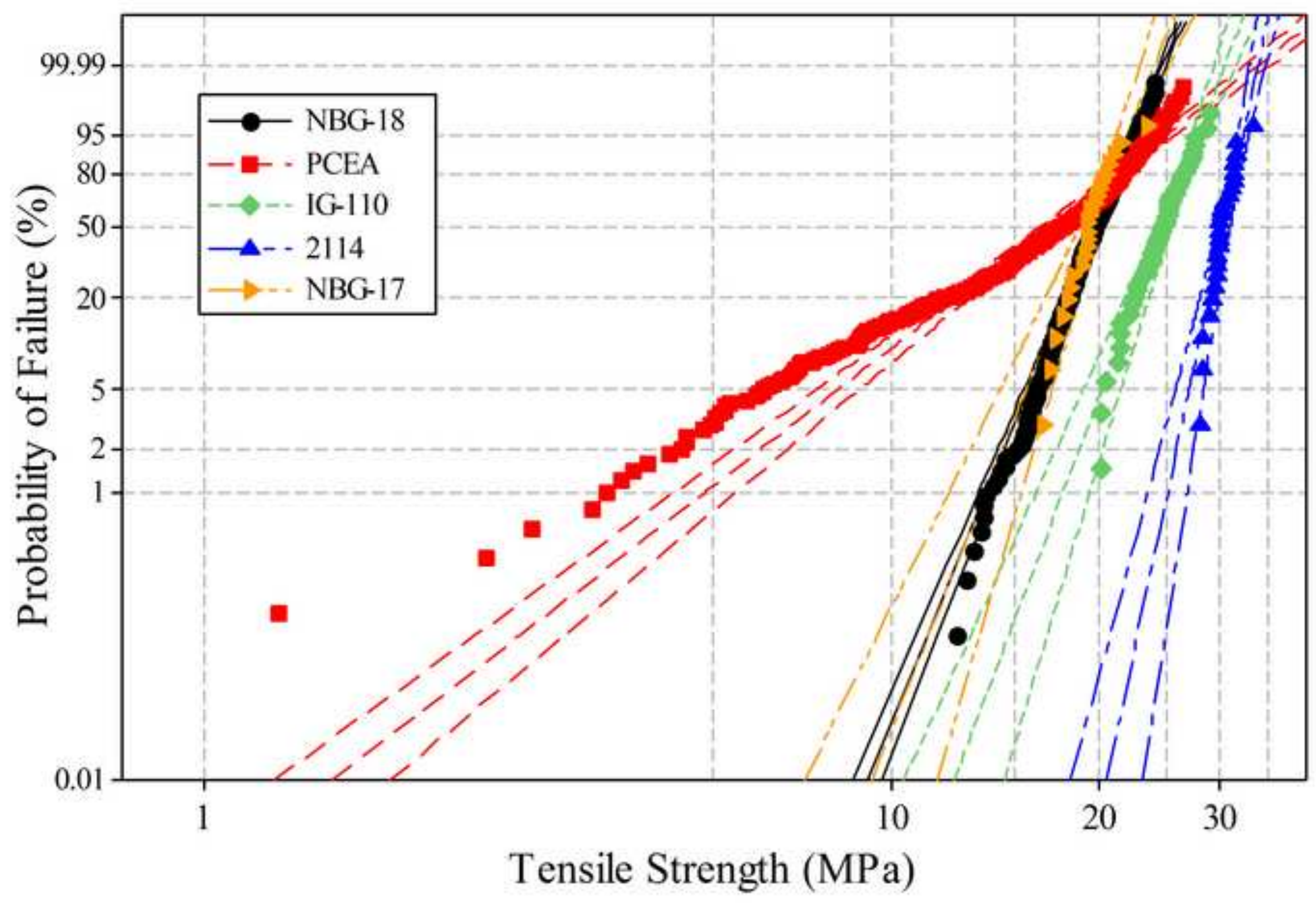



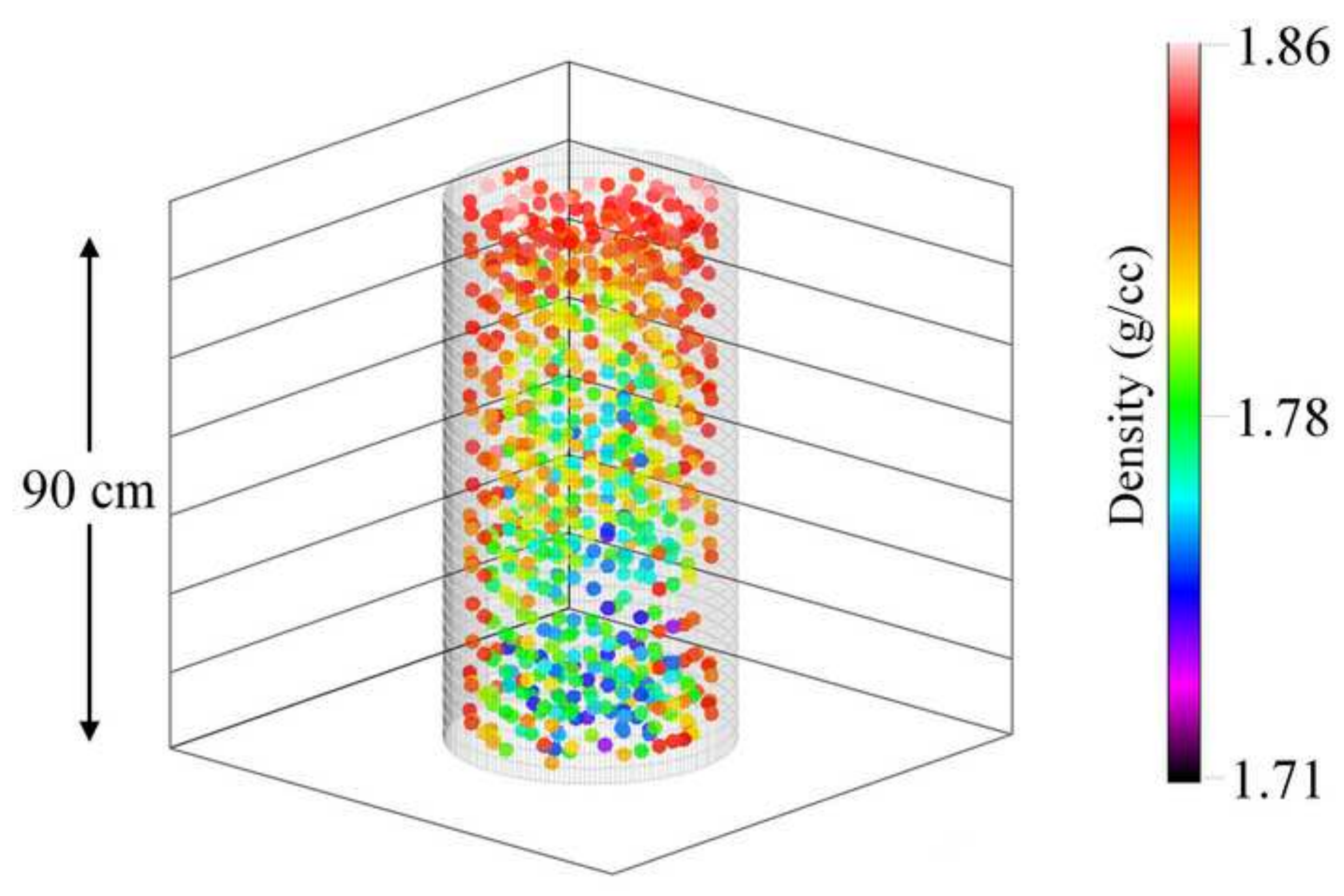

1.71 

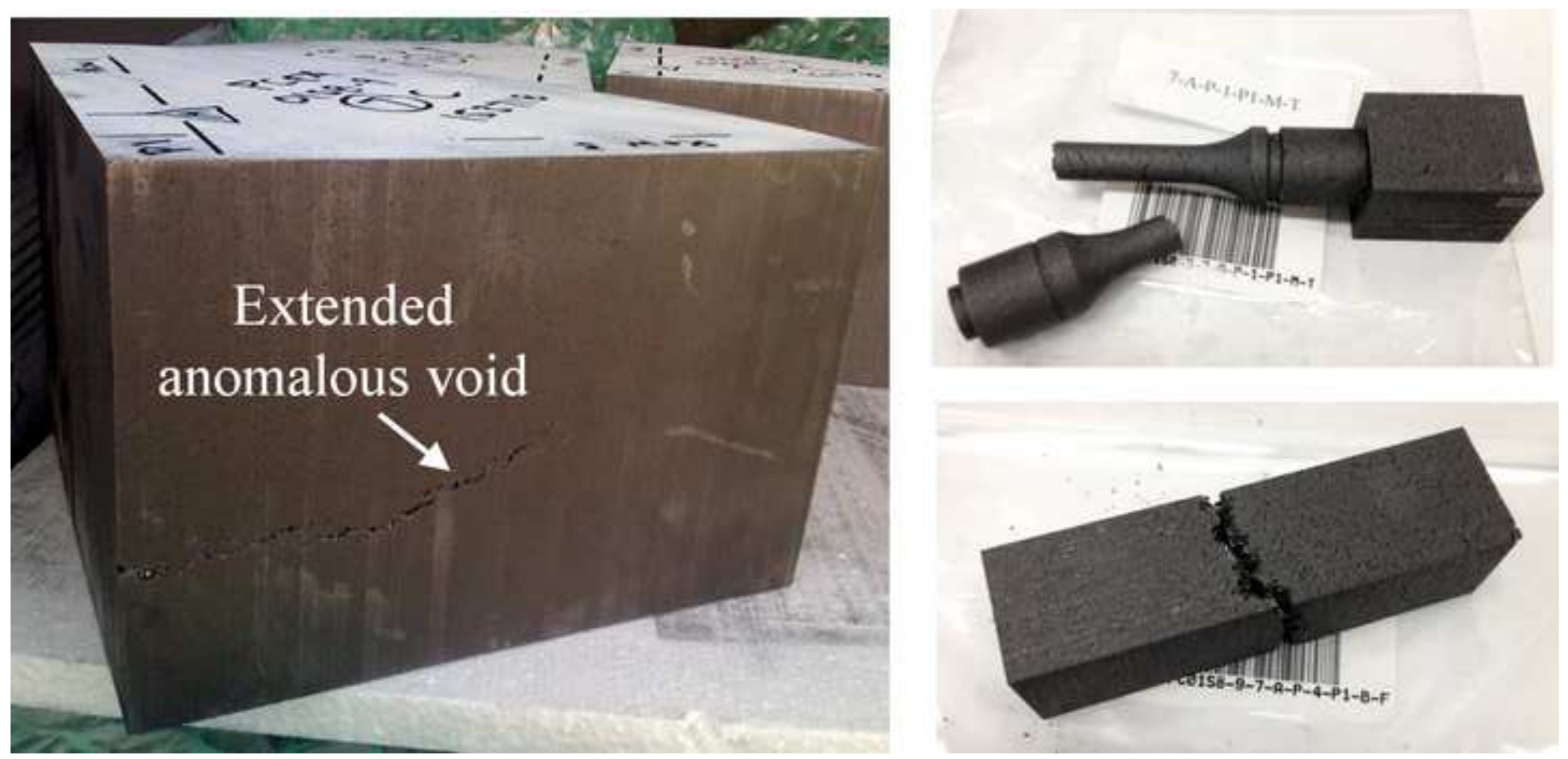


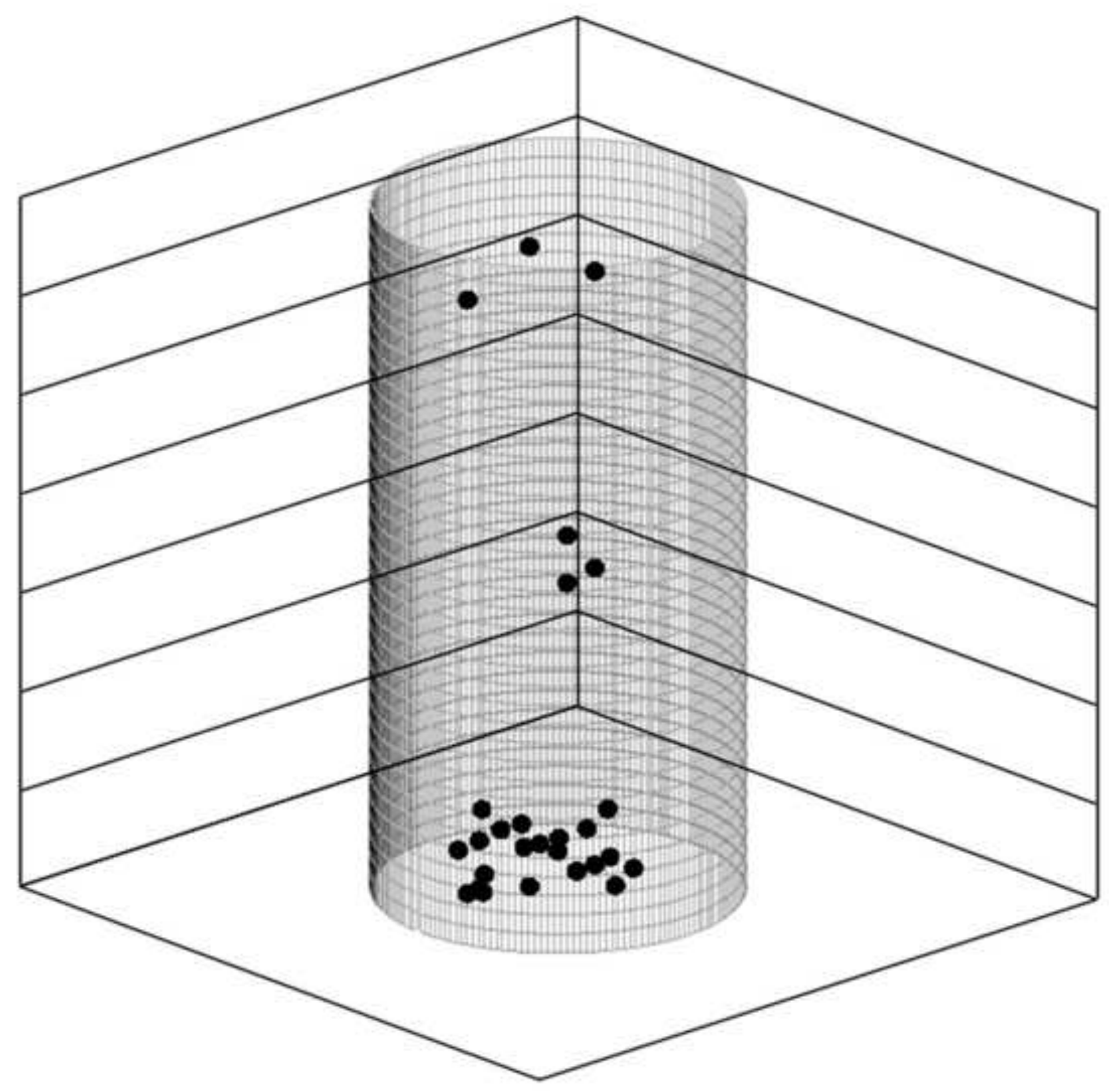




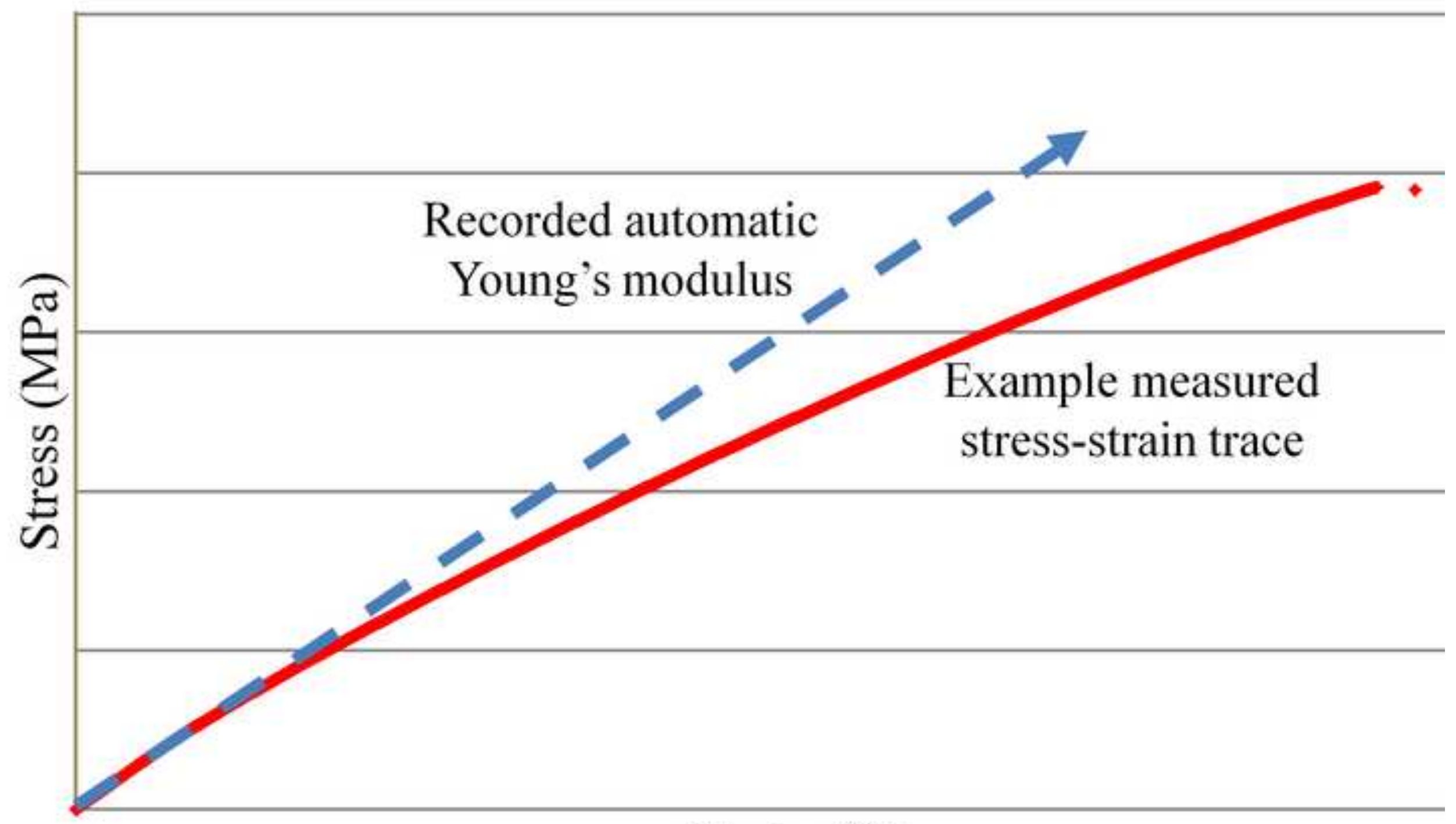

Strain (\%) 


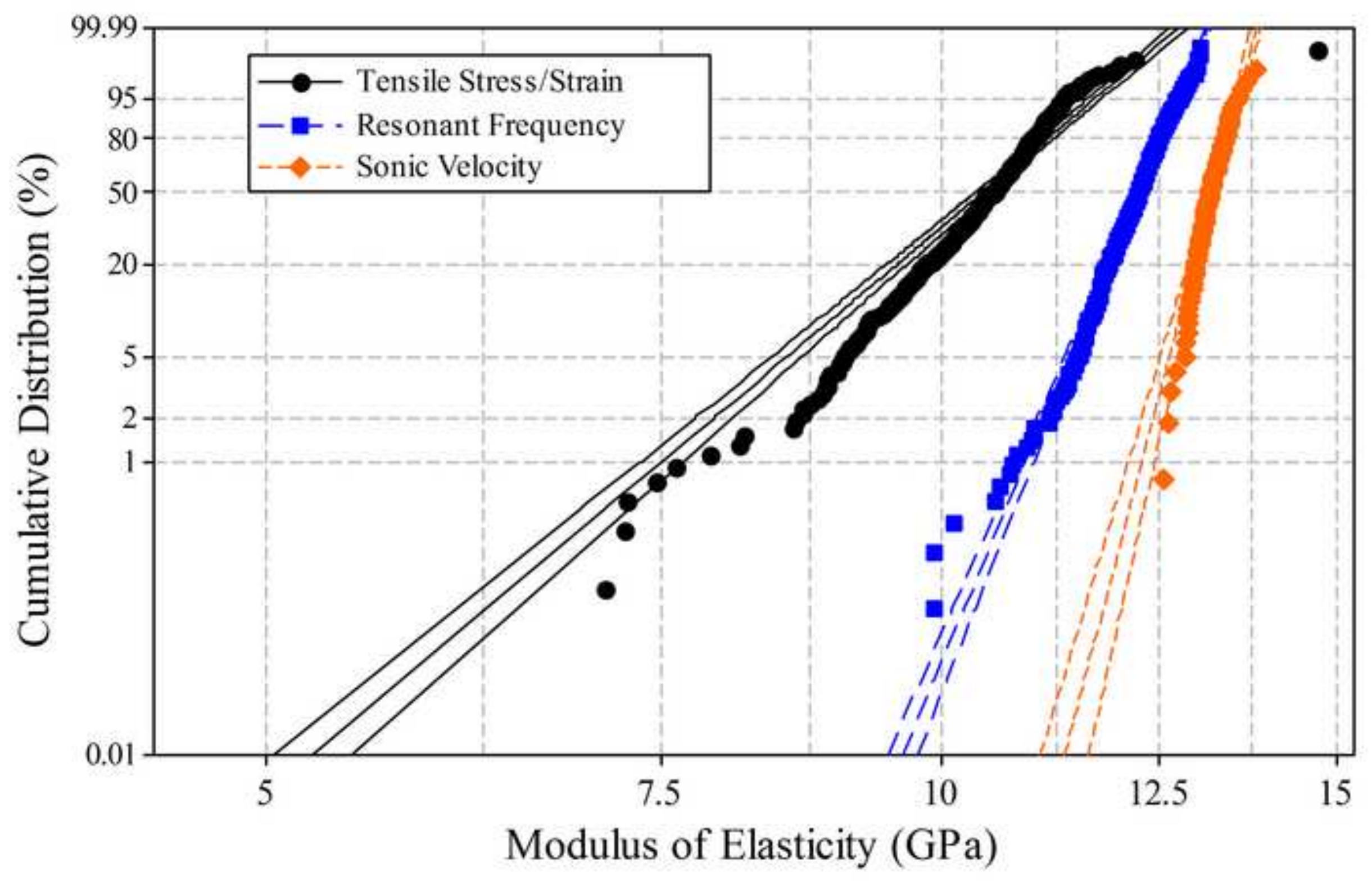




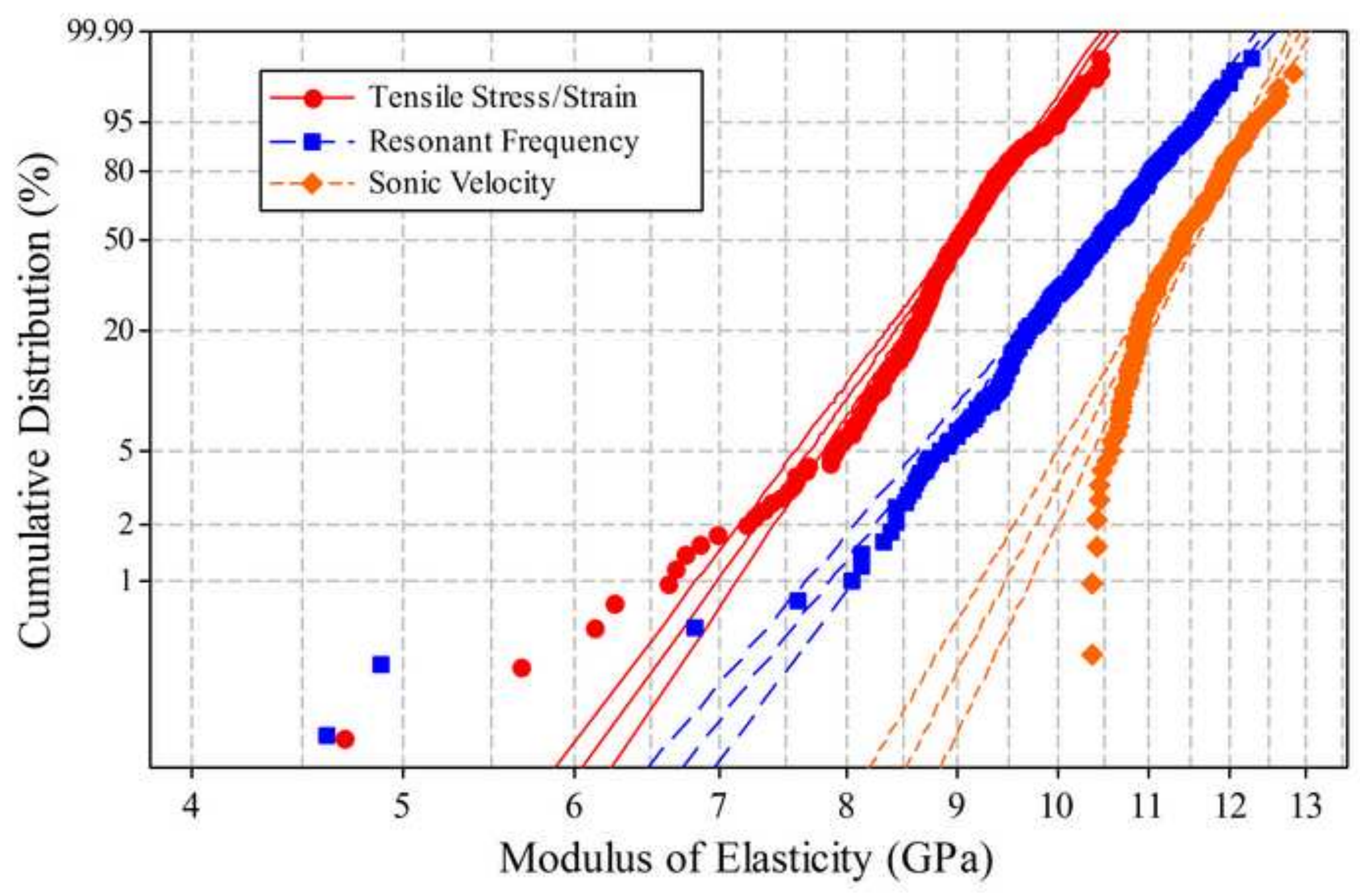

